\title{
SELECIONANDO OS MATERIAIS PARA AS PRÓXIMAS GERAÇÕES*
}

\author{
Jéssica Willveit Ferezin Vieira ${ }^{1}$ \\ Felipe Beluche Lima ${ }^{2}$ \\ William Naville ${ }^{37}$
}

\section{Resumo}

Produtos de consumo em massa causam um grande impacto ambiental, destaca-se que as empresas podem se beneficiar com ações, como a inclusão de objetivos de redução de impacto ambiental e sustentabilidade, nas etapas de desenvolvimento, projeto e seleção de materiais sem aumento nos aspectos econômicos. Três produtos de consumo em massa foram estudados: escova de dentes, embalagem de marmita e blister de medicamentos. Por meio de estimativas e simulações, utilizando-se a ferramenta de energia incorporada do software Eco Audit $\AA$, determinou-se o consumo de energia incorporada e as emissões de $\mathrm{CO}_{2}$ para o uso de alguns materiais em potencial. Simultaneamente, considerou-se nos requisitos funcionais e geométricos a preocupação com o meio ambiente na etapa de projeto. O resultado foi que estes produtos de consumo em massa geram um grande impacto ambiental e a seleção de materiais em conjunto com os requisitos funcionais e geométricos, tendo como objetivo adicional uma redução do impacto ambiental, gera redução do gasto de energia incorporada e consequentemente a redução nas emissões de $\mathrm{CO}_{2}$.

Palavras-chave: Seleção de materiais; Impacto ambiental; Produtos de consumo em massa; Energia incorporada

\section{SELECTING MATERIALS FOR THE NEXT GENERATIONS}

\section{Abstract}

Mass consumer products cause a great environmental impact. It is highlighted that companies can benefit from actions, such as the inclusion of environmental impact reduction and sustainability goals, in the stages of development, design and selection of materials without any increase in economic aspects conditions. Three products of mass consumption were studied: toothbrush, packed lunch and medication blister. By means of estimates and simulations, using the built-in energy tool of the Eco Audit ${ }^{\circledR}$ software, the consumption of incorporated energy and the CO2 emissions for the use of some potential materials was determined. Simultaneously, the concern with the environment in the design stage was considered in the functional and geometric requirements. The result was that these mass consumer products generate a great environmental impact and the selection of materials in conjunction with the functional and geometric requirements, with the additional objective of reducing the environmental impact, generating a reduction of the incorporated energy expenditure and consequently reducing Emissions.

Keywords: Materials Selection; Environmental impact; Mass consumer products; Embodied energy.

\footnotetext{
Engenharia de Materiais, Centro Universitário da FEl, São Bernardo do Campo, São Paulo, Brasil. Engenharia de Materiais, Centro Universitário da FEl, São Bernardo do Campo, São Paulo, Brasil. Engenharia Industrial Mecânica, Mestre em Ciências, Professor, Engenharia de Materiais, Centro Universitário da FEl, São Bernardo do Campo, São Paulo, Brasil.
} 


\section{INTRODUÇÃO}

Atualmente, sabe-se que a indústria se encontra em constante expansão e a população está vivendo a chamada Sociedade de consumo. Esta fase é marcada pela tendência ao consumismo (um tipo de despesa impulsiva e muitas vezes irracional) resultado de estratégias de marketing extremamente sedutoras e agressivas desenvolvidas pelas organizações para venderem massivamente seus produtos. É importante que as empresas se preocupem também com a reciclagem destes produtos, pois caso não seja possível dar um destino apropriado e proporcional à quantidade de vendas, o impacto resultante ao meio ambiente será cada vez mais agravado ${ }^{[1]}$. Como exemplo, estima-se que há o consumo de 1 milhão de sacolas plásticas por minuto no mundo inteiro, sendo este considerado o resíduo com maior impacto e degradação ao meio ambiente. De acordo com o Programa das Nações Unidas para o Meio Ambiente, $70 \%$ de todos os detritos encontrados no mar são de plástico, sendo que 46 mil pedaços flutuam a cada 2,58 km quadrados de oceano[2].

Projeto para o meio ambiente pode ser interpretado como a mobilização em projeto de produtos para corrigir a degradação ambiental, a escala de tempo deste modo de pensar é de cerca de uma década. Projeto para sustentabilidade é a visão de longo prazo, décadas ou séculos, para adaptação a um estilo de vida que atende as necessidades presentes sem comprometer as necessidades das próximas gerações $^{[3]}$. Estão sendo incorporados aspectos legais no mundo inteiro sobre sustentabilidade, a exemplo do Brasil que recentemente implementou a Política Nacional de Resíduos Sólidos (Lei №. 12305, de 12 de agosto de 2010). Juntamente com o fato de essas exigências legais possuírem uma tendência de se tornarem cada vez mais rígidas, dada a atual gravidade da situação ambiental, existe também o crescente interesse do consumidor em questões de sustentabilidade e, portanto, importantes pesquisas sobre o tema vêm sendo estimuladas. Na maioria dos casos, os principais problemas quanto às pesquisas estão vinculados com a complexidade dos estudos, custo elevado, seu tempo de implantação e com o fato de solucionarem problemas de poucos produtos. Sendo assim, o desafio de correr contra o tempo para promover a redução do impacto ambiental se torna uma variável de extrema importância, pois é necessário tomar providências urgentes na prevenção ambiental e fiscalização em todos os segmentos da indústria.

Então, é imprescindível responder à questão: $O$ que pode ser feito de imediato para reduzir o impacto ambiental desses produtos?

Pensar nas questões ambientais desde os primeiros estágios do desenvolvimento de qualquer produto pode ser uma excelente maneira de evitar problemas ambientais durante o seu ciclo de vida. Além disso, permite-se a obtenção de benefícios para a empresa em relação à competitividade através da redução de custos, otimização do uso de materiais e energia, redução da disposição de resíduos, desenvolvimento de processos mais eficientes e melhoria da imagem da empresa e/ ou marca ${ }^{[4]}$. A Harvard Business Review (2007) ${ }^{[5]}$ publicou uma coletânea sobre o tema, sendo que em muitos de seus artigos são discutidas estratégias de negócios focando-se na sustentabilidade socioambiental. Os autores defendem que as organizações, uma vez que há exigências tanto do consumidor, quanto do ponto de vista de regulação do Estado, devem investir nas oportunidades de negócio com esta temática.

Para que se possa agregar valor aos produtos, muitas empresas investem em designs arrojados para atrair a atenção do consumidor, sendo que, pelo interesse 
em prevalecer seu lucro, os componentes podem se tornar um empecilho ecológico. Pesquisa Akatu (2012) ${ }^{[6]}$ permite constatar o crescente entendimento por parte da população sobre as questões de sustentabilidade ao longo dos anos e, por consequência disto, a decisão do consumidor na hora da escolha de um produto está cada vez mais relacionada com a postura das empresas quanto à sustentabilidade. Isto pode ser um ótimo indício de que as indústrias podem começar a investir no Marketing "verde".

Uma ferramenta muito utilizada para estimar o impacto ambiental causado por alguns produtos é a energia incorporada. Para a utilização desta ferramenta, é necessário conhecer o ciclo de vida do produto, levando-se em consideração a energia total necessária para sua produção, abrangendo etapas desde extração da matéria prima até a distribuição do produto no mercado ${ }^{[7]}$. Ao reduzir o consumo de energia agregada nas etapas de produção, por consequência, reduz-se a produção de $\mathrm{CO}_{2}$ gerado no ciclo de vida do produto, já que são parâmetros proporcionais [7].

Outro tópico importante que também pode ser avaliado nesta ferramenta para análise do ciclo de vida energético é a energia de operação (termo adotado principalmente para edificações), ou seja, energia consumida durante a vida útil de um material. Esta ferramenta já vem sendo muito utilizada em materiais de construção, sendo que iniciativas de apoio do governo vêm a oferecer grande suporte em seu desenvolvimento e aplicação, visando à diminuição da demanda energética[8].

O método de avaliação do ciclo de vida do produto em termos de energia conta com auxílio de softwares disponíveis no mercado. Estes promovem a seleção de materiais e são capazes de realizar simulações energéticas na fase do projeto e identificar ineficiências ecológicas, reduzindo-se assim o impacto ambiental. A implementação destes softwares requer baixos investimentos e não compromete a eficiência da produção, como exemplo, pode-se citar: ECOTEC, Energy Plus (gratuito) e Design Builder, utilizados em edificações, além do ECO Efficiency Improvement Tool ${ }^{\mathrm{TM}}$ e CES EduPack ${ }^{\circledR}$ (ECO Audit®) que são aplicados para materiais no geral.

O objetivo deste trabalho é, pelo uso da ferramenta de energia incorporada do software Eco Audit $\AA$, demostrar através de exemplos, que a estratégia de seleção de materiais associada à redução do impacto ambiental, quando considerados os produtos de consumo em massa, representa uma redução considerável no consumo de energia e, portanto, nas emissões de gases do efeito estufa.

\section{MATERIAIS E MÉTODOS}

Os procedimentos de análise e aquisição de dados partiram das seguintes etapas:

\section{Escolha dos produtos}

Para a escolha dos produtos utilizados neste trabalho, foram considerados os seguintes critérios: Seleção de produtos de consumo em massa, uma vez que reconhecidamente causam um grande dano ao meio ambiente; Produtos de baixa reciclabilidade, para que sejam demonstradas as alternativas que aumentem a possibilidade de dar um destino mais adequado para os materiais no seu fim de vida (EoL). A partir destes princípios, selecionaram-se os seguintes produtos: escova de dentes, embalagem de marmita e blister de medicamentos. 


\section{Medição e pesagem dos produtos}

Os diferentes componentes contidos no produto foram separados de seu conjunto a fim de se medir a massa e a espessura de cada elemento, foram feitas estimativas de aumento de volume para compensar a troca de materiais. Em seguida, os valores de massa estimados para os componentes foram inseridos na ferramenta do software Eco Audit $\AA$, as estimativas são explicadas na Tabela 1.

Tabela 1- Procedimento utilizado para obtenção das massas nos exs. estudados Método de obtenção das massas

\begin{tabular}{c|c|c}
\hline Escova de Dentes & Embalagem de marmita & Blister de Medicamentos \\
\hline $\begin{array}{c}\text { Pesagem direta do cabo } \\
\text { e da cabeça, } \\
\text { separadamente. }\end{array}$ & $\begin{array}{c}\text { Pesagem da } \\
\text { alumínio. Por tampa, amostra de } \\
\text { aumento de volume, foram calculadas as a do } \\
\text { massas das embalagens em outros } \\
\text { materiais. }\end{array}$ & $\begin{array}{c}\text { Cálculo das massas a partir do } \\
\text { volume e da densidade dos } \\
\text { componentes. Por meio do } \\
\text { volume, estimativa das massas } \\
\text { das embalagens em outros } \\
\text { materiais. }\end{array}$ \\
\hline
\end{tabular}

\section{Utilização do Software}

Durante o ciclo de vida do produto são consideradas algumas etapas: material, fabricação, transporte, uso e descarte. Em todas estas etapas o aumento da massa é diretamente proporcional ao aumento do consumo de energia e emissões de $\mathrm{CO}_{2}$. No caso do descarte, pode haver a recuperação da energia consumida, ou o crédito de carbono conseguido por meio da reciclagem, reuso, remanufatura, aproveitamento em um ciclo de produto de qualidade inferior ou queima. $\mathrm{O}$ descarte em aterro sanitário é a destinação menos nobre ao produto, não há recuperação, provocando impacto ao meio ambiente. Com o software é possível identificar qual a etapa do ciclo de vida dos produtos que gera o maior impacto. Isto é feito a partir de gráficos gerados com base nos fatores Consumo de Energia e consequentemente Pegada de $\mathrm{CO}_{2}$. Neste trabalho, haverá a preocupação em estimar a energia incorporada e pegada de $\mathrm{CO}_{2}$ considerando-se as etapas: material, fabricação e descarte, devido ao fato destes quesitos serem os mais relevantes para a estratégia estudada. Vale acrescentar que uma vez que há a preocupação em reduzir a massa do material, os outros quesitos, como transporte e uso do produto serão beneficiados.

\section{Análise dos resultados}

Para cada produto simulado obteve-se o resultado dos cálculos realizados para a energia incorporada e pegada de $\mathrm{CO}_{2}$. Foram analisados quanto ao melhor desempenho, menor energia incorporada e pegada de $\mathrm{CO}_{2}$, ou seja, vantagem quanto ao projeto mais sustentável.

\section{RESULTADOS E DISCUSSÃO}

Geralmente, um componente estrutural possui funções físicas: suportam cargas, transmitem calor, armazenam energia e satisfazem os requisitos funcionais que são especificados pelo projeto. Para isso, devem também apresentar parâmetros geométricos, forma e posição de montagem adequadas dos componentes em relação a sua função física. Também se leva em consideração as propriedades do material para que sejam atendidas as condições impostas pelo projeto oriundas dos requisitos funcionais e parâmetros geométricos. Sendo assim, ao se aperfeiçoarem separadamente os requisitos funcionais, parâmetros 
geométricos ou propriedades do material, o resultado proporciona um melhor desempenho do componente ${ }^{[9]}$.

Quando se observa o problema do ponto de vista da redução do impacto ambiental, é necessário incluir a capacidade de reciclagem e a redução da energia incorporada, bem como, a redução das emissões de gases de efeito estufa, objetivando-se a maior recuperação possível de energia e créditos de carbono no fim da vida do produto (EoL). Compreendendo-se que a importância e o impacto desses fatores dependem do fato de que para alguns produtos, como aqueles de consumo em massa, os números são enormes e crescem com o aumento da população. Pode-se dizer que é preciso analisar esses fatores sob a ótica da sustentabilidade, pois é preciso pensar nos requisitos funcionais e geométricos evitando o excesso de massa, que significa um aumento do consumo de energia e emissão de gases do efeito estufa, além de fatores funcionais que aumentam a capacidade de reciclagem, bem como considerar o uso de materiais recicláveis e ou biodegradáveis. O projetista deve prever ainda o destino do produto após o fim de seu ciclo de vida.

Portanto, levando estes fatores em consideração, foi possível analisar e simular características de alguns produtos de consumo em massa (como escova de dentes, embalagem de marmita e blister de medicamentos), além de propor algumas alternativas para torná-los mais sustentáveis. Para a etapa das simulações, foi necessária uma estimativa do número de escovas de dentes utilizadas no Estado de São Paulo. Os dados estatísticos foram retirados do IBGE, conforme mostrado na Tabela 2.

Tabela 2 - Dados da população em São Paulo, a partir dos dados do IBGE, 2016

\begin{tabular}{c|c|c}
\hline Total da População & $93,65 \%$ a partir de 4 anos & $9,09 \%$ mais de 60 anos \\
\hline 44.829 .424 & 41.982 .756 & 4.074 .995 \\
\hline
\end{tabular}

\section{Escova de Dentes}

Algumas características de produtos poliméricos podem atrapalhar na reciclagem e, portanto, muitos produtos acabam em aterros ou em destinos inapropriados. Dentre estas características, pode-se citar: sujidade de embalagens, presença de impressão silk screen, o mesmo material com cores diferentes, presença de contaminantes (como selos de alumínio), materiais sem identificação correta da embalagem, entre outros ${ }^{[4]}$. A Figura 1 mostra algumas características de cores que são mais ou menos favoráveis para a reciclagem.

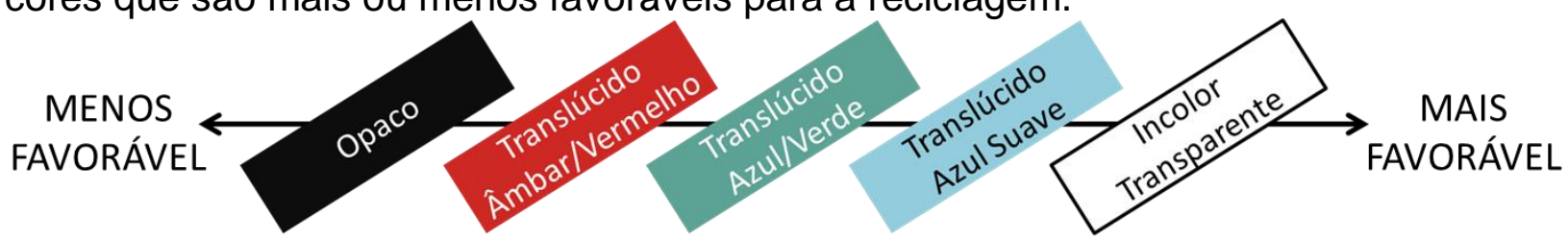

Figura 1. Cores dos materiais poliméricos que prejudicam a reciclagem

O material escolhido para simulação do cabo e da base da cabeça foi o SAN, Copolímero de Estireno e Acrilonitrila. Foram simuladas três situações diferentes para a escova de dentes, Figura 2:

(a) considerando-se o produto com mistura de materiais, opaco, portanto na simulação realizada, o destino escolhido para este tipo de escova de dentes foi o aterro; 
(b) simulação de uma escova de dentes com o cabo de apenas um material, translúcido, considerando a remoção da cabeça por meio de corte, para reciclagem do cabo;

(c) utilizando apenas um material para o cabo, translúcido, e considerando a possibilidade de remoção e troca da cabeça, ou seja, um conjunto de 3 (três) cabeças removíveis para apenas 1 cabo de escova, desta forma haverá uma redução de massa do produto, economia de dois cabos, para três escovas, mantendo o cabo reciclável. Este tipo de funcionalidade já está disponível no mercado.

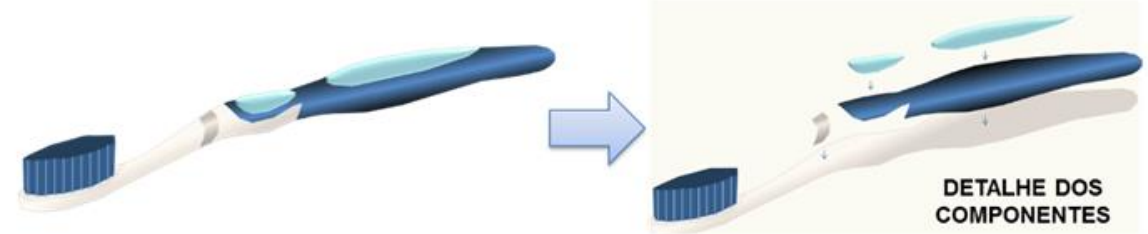

(a) Escova com mistura de materiais

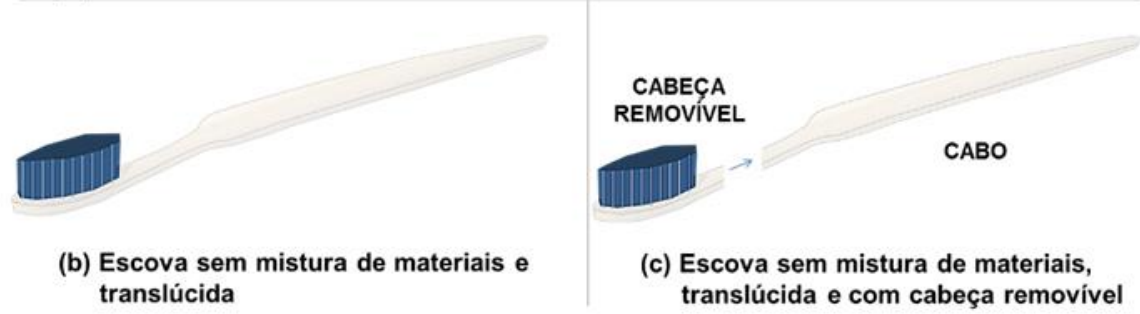

Figura 2. llustração da escova de dentes: (a) com mistura de material; (b) apenas um material-translúcido (c) sem mistura- translúcido e com cabeça removível

Tendo em vista a recomendação de troca de escova de dente a cada 3 meses após seu uso diário e considerando o consumo da população acima de 4 anos (correspondente a 93,65\%), o total de escovas de dentes consumidas em um ano em São Paulo é de 167.931.024.

Pela associação dos produtos, fica evidente a redução de massa proporcionada pela escova de dente sem mistura de material e com cabeça removível. Como se pode observar na Tabela 3, não há a possibilidade de reciclagem do componente "cabeça" por apresentar uma considerável mistura de materiais (cerdas de nylon e pinças de material metálico para fixar as cerdas na cabeça), inerente a suas condições de fabricação e tecnologia de escovação incorporada, ou seja, apenas para os cabos nas situações sem mistura de materiais e translúcidos foram determinados o fim de vida (EoL) de reciclagem e os demais encaminhados para aterro.

Para dar continuidade ao procedimento utilizando a ferramenta do software, os valores de massa do produto, ou seja, do cabo e da cabeça da escova de dentes, como sendo $14,30 \mathrm{~g}$ e $4,14 \mathrm{~g}$, respectivamente, foram inseridos na simulação conjuntamente com a estimativas das quantidades de componentes mencionadas anteriormente. 
Tabela 3 - Resumo dos parâmetros relevantes para a simulação no software ESCOVA DE DENTES

\begin{tabular}{|c|c|c|c|c|}
\hline Produto & Componentes & Quantidade & Componentes & EoL \\
\hline (a) Com mistura de & Cabeça & \multirow{5}{*}{167.931 .024} & Cabeça & Aterro \\
\hline Material & Cabo & & Cabo & Aterro \\
\hline \multirow{2}{*}{$\begin{array}{l}\text { Sem mistura de } \\
\text { Material }\end{array}$} & Cabeça & & Cabeça & Aterro \\
\hline & Cabo & & Cabo & Reciclagem \\
\hline (c) Sem mistura de & Cabeça & & Cabeça & Aterro \\
\hline $\begin{array}{l}\text { Material com cabeça } \\
\text { removível }\end{array}$ & Cabo & 55.977 .008 & Cabo & Reciclagem \\
\hline
\end{tabular}

Com os dados dispostos na Tabela 4, nota-se entre as situações (a) e (b), ou seja, entre o produto contendo a mistura de materiais e a escova com o cabo fabricado por apenas um tipo de material translúcido, que há uma redução dos dois parâmetros totais finais, tanto em termos de gasto de energia, redução de $44 \%$, quanto de emissões de $\mathrm{CO}_{2}$, redução de $39 \%$. A diminuição é equivalente à recuperação do potencial de energia (EoL) pela condição de reciclagem do cabo do produto (-141.600.000 MJ e $-5.085 .000 \mathrm{~kg}$ de $\mathrm{CO}_{2}$ ), recuperando-se parte da energia incorporada para fabricação da escova.

Quando se comparam as condições (a) e (c) simuladas, em que além da reciclagem, há a redução do número de cabos como alternativa de redução do impacto ambiental, nota-se uma redução muito significativa de aproximadamente $68 \%$ no gasto de energia, bem como de emissões de $\mathrm{CO}_{2}$.

\section{Embalagem de marmita}

Para a estimativa do número de marmitas utilizadas em um ano, tomou-se como base o Setor da Construção Civil, que apesar de ter registrado aumento no nível de desemprego durantes os anos anteriores, é o ramo que apresentou maior crescimento no país e um dos ambientes mais propícios para consumo de marmitas.

Tabela 4 - Resultado da simulação com o Eco Audit $\AA$

EMBALAGEM DE MARMITA

\begin{tabular}{|c|c|c|c|}
\hline Produto & Energia Incorporada (MJ) & $\begin{array}{c}\text { Potencial de Energia } \\
\text { EoL (MJ) }\end{array}$ & $\begin{array}{c}\text { Energia Total } \\
\text { (MJ) }\end{array}$ \\
\hline $\begin{array}{l}\text { (a) Com Mistura de } \\
\text { Materiais }\end{array}$ & 339.731 .792 & 0 & 339.731 .792 \\
\hline $\begin{array}{l}\text { (b) Sem Mistura de } \\
\text { Materiais, translúcido }\end{array}$ & 331.100 .000 & -141.600 .000 & 189.500 .000 \\
\hline $\begin{array}{l}\text { (c) Sem Mistura, translúcido/ } \\
\text { cabeça Removível }\end{array}$ & 154.700 .000 & -47.210 .000 & 107.490 .000 \\
\hline Produto & Pegada de $\mathrm{CO}_{2}(\mathrm{~kg})$ & $\begin{array}{l}\text { Potencial de } \mathrm{CO}_{2-} \\
\text { EoL (kg) }\end{array}$ & $\mathrm{CO}_{2}$ Total $(\mathrm{kg})$ \\
\hline (a) Com Mistura de Materiais & 14.652 .068 & 0 & 14.652 .068 \\
\hline $\begin{array}{l}\text { (a) Sem Mistura de } \\
\text { Materiais, translúcido }\end{array}$ & 14.000 .000 & -5.085 .000 & 8.915 .000 \\
\hline $\begin{array}{l}\text { (b) Sem Mistura, translúcido/ } \\
\text { cabeça Removível }\end{array}$ & 6.371 .000 & -1.695 .000 & 4.676 .000 \\
\hline
\end{tabular}

Cerca de 769 mil trabalhadores em obra estavam ativos em fevereiro desde ano no estado de São Paulo ${ }^{[10]}$. Ao se estimar o consumo diário de marmitas destes 
operários entre $70-75 \%$, tem-se que, aproximadamente, 17,8 milhões de refeições são distribuídas todos os meses apenas no Estado de São Paulo.

Para a simulação no software em função das características das marmitas, Figura $3(\mathrm{~A})$, coletou-se os valores de massa e espessura do produto usualmente comercializado (marmita de alumínio), como sendo $7,59 \mathrm{~g}$ e 0,03 mm, respectivamente. Além disso, previu-se a massa de uma marmita fabricada com isopor através de sua densidade (massa=3,42 g), Figura $3(B)$ e fez-se a mesma associação para a fabricação de marmitas de papel (massa=22,8 g), Figura $3(\mathrm{C})$.

Não foi considerada a hipótese de reciclagem do produto devido a contaminação com restos de alimentos. Este produto, em geral, é descartado em lixo comum.

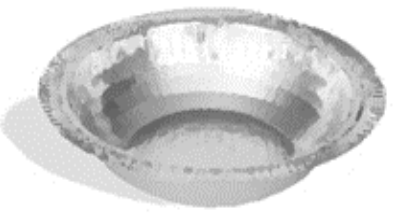

(A) Marmita de Alumínio

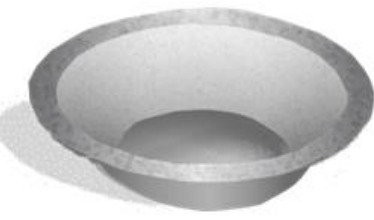

(B) Marmita de Isopor

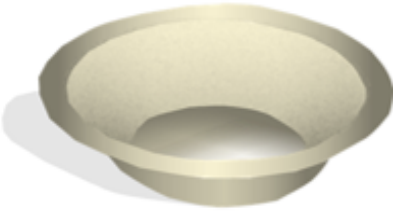

(C) Marmita de Papel

Figura 3. Ilustração da marmita: (A) de Alumínio; (B) de Isopor e (C) de Papel.

Por meio dos resultados obtidos e dispostos na Tabela 5, observa-se que o uso inconsciente do produto fabricado em alumínio apresenta um valor excessivo de energia incorporada e pegada de $\mathrm{CO}_{2}$. Há cerca de $75 \%$ de redução de energia por meio da substituição pelo isopor e $31 \%$, no caso do papel. Apesar da grande diferença no uso do isopor, vale ressaltar a biodegradabilidade do papel em termos de impacto ambiental, pois o isopor apresenta fatores prejudiciais em função do resíduo permanente no meio ambiente. Porém, em termos de emissões de $\mathrm{CO}_{2}$, ambas as substituições apresentam pequena diferença, comparando-se com a embalagem de alumínio, obteve-se aproximadamente $81 \%$ de redução para a embalagem de isopor e $76 \%$ para a de papel.

Tabela 5- Resultado da simulação com o Software Eco Audit ${ }^{\circledR}$ EMBALAGEM DE MARMITA

\begin{tabular}{|c|c|c|c|}
\hline Produto & $\begin{array}{c}\text { Energia Incorporada } \\
(\mathrm{MJ})\end{array}$ & $\begin{array}{c}\text { Potencial de Energia EoL } \\
\text { (MJ) }\end{array}$ & Energia Total (MJ) \\
\hline Alumínio & 324.876 .044 & \multirow{3}{*}{0} & 324.876 .044 \\
\hline Isopor & 80.658 .904 & & 80.658 .904 \\
\hline Papel & 225.460 .941 & & 225.460 .941 \\
\hline Produto & Pegada de $\mathrm{CO}_{2}(\mathrm{~kg})$ & $\begin{array}{c}\text { Potencial de } \mathrm{CO}_{2-} \text { EoL } \\
(\mathrm{kg})\end{array}$ & $\mathrm{CO}_{2}$ Total $(\mathrm{kg})$ \\
\hline Alumínio & 21.102 .424 & \multirow{2}{*}{0} & 21.102 .424 \\
\hline Isopor & 3.644 .293 & & 3.644 .293 \\
\hline Papel & 4.983 .489 & & 4.983 .489 \\
\hline
\end{tabular}

É importante avaliar a fabricação dos produtos em função de energia incorporada, no caso do alumínio, a reciclagem é conhecida e altamente favorável para recuperação energética, fato que deve ser considerado para evitar-se o desperdício de recursos naturais importantes para sociedade, por exemplo, destinando este material para o aterro. 


\section{Blister de Medicamentos}

De acordo com a Agência Senado (2015), o mercado consumidor de medicamentos controlados apresentou um aumento exacerbado de $161 \%$ comparado com o ano de 2009. Esta estimava é equivalente a 295 mil caixas comercializadas durante 0 ano anterior. Junto ao crescimento do mercado farmacêutico, as embalagens utilizadas para o armazenamento seguro do medicamento apresentam componentes de diferentes materiais. No caso do blister de medicamento, os componentes geralmente presentes são feitos de uma junção de material polimérico (base de PVC) com um fechamento de alumínio, conforme ilustrado na Figura 4, sendo este o produto que, aparentemente, apresenta maior consumo. Porém, uma pequena fração de medicamentos utilizam o alumínio em ambos os lados.

O Instituto Brasileiro de Geografia e Estatística[11] apresenta que 9,09\% da população no estado de São Paulo em 2016 é constituída de pessoas com 65 anos ou mais, ou seja, a faixa etária de maior potencial contribuinte para o consumo de medicamentos. A projeção do Instituto acrescenta que esta porcentagem de idosos apenas tende a aumentar nos próximos anos com o aumento da expectativa de vida da população.

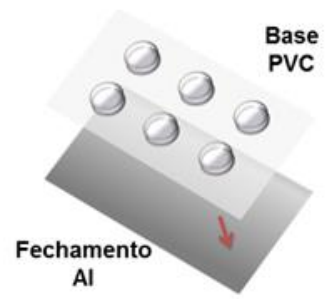

(A) Componentes do Blister

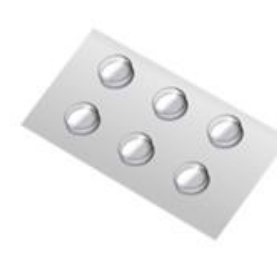

(B) Blister Completo

Figura 4. Ilustração de um blister de medicamentos com ênfase no uso de dois materiais, alumínio e PVC.

Com base nos dados, considerando-se uma média de consumo de 5 diferentes tipos de remédios ao mês contendo 2 blisters em cada caixa para cada idoso, tem-se que cerca de 3.200 .000 blisters de medicamentos estão presentes anualmente no cotidiano da população idosa apenas no Estado de São Paulo ${ }^{[12]}$.

Para as simulações, foram feitas medições do blister mais utilizado atualmente, que é o feito a partir da união do PVC com o alumínio. A partir dos resultados obtidos foi feita uma estimativa para mais 3 situações, onde a reciclagem é possível: Blister feito apenas de alumínio, Blister apenas de PVC e Blister de papel. A Tabela 6 mostra o resumo dos parâmetros relevantes para a simulação no software.

Para a simulação do software em função das características do blister, calcularam-se as massas a partir das dimensões e densidade do produto usualmente comercializado (alumínio-PVC). Por meio da densidade e das dimensões, comprimento, largura e espessura, medidas no blister utilizado como amostra, respectivamente $(0,11 \times 0,05 \times 0,32) \mathrm{m}$ para a base e $(0,11 \times 0,05 \times 0,031)$ $\mathrm{m}$ para o fechamento, calcularam-se as massas obtidas para cada situação (alumínio- alumínio, alumínio-PVC, PVC-PVC e papel-papel) respectivamente: $1,865 \mathrm{~g} ; 2,743 \mathrm{~g} ; 3,000 \mathrm{~g}$ e $1,617 \mathrm{~g}$. 
Tabela 6 - Resumo dos parâmetros relevantes para a simulação do Blister no Software Eco Audit ${ }^{\circledR}$

\begin{tabular}{|c|c|c|c|c|}
\hline Blister: & Componentes & Quantidade & Material & EoL \\
\hline \multirow{2}{*}{$\begin{array}{l}\text { Alumínio- } \\
\text { Alumínio }\end{array}$} & Fechamento & \multirow{8}{*}{3.200 .000} & Alumínio & \multirow{2}{*}{ Reciclagem } \\
\hline & Base & & Alumínio & \\
\hline \multirow{2}{*}{$\begin{array}{l}\text { Alumínio- } \\
\text { PVC }\end{array}$} & Fechamento & & Alumínio & \multirow{2}{*}{ Aterro } \\
\hline & Base & & PVC & \\
\hline \multirow{2}{*}{ PVC-PVC } & Fechamento & & PVC & \multirow{2}{*}{ Reciclagem } \\
\hline & Base & & PVC & \\
\hline \multirow{2}{*}{$\begin{array}{l}\text { Papel- } \\
\text { Papel }\end{array}$} & Fechamento & & Papel & \multirow{2}{*}{ Reciclagem } \\
\hline & Base & & Papel & \\
\hline
\end{tabular}

De acordo com a simulação, Tabela 7 , a primeira consideração a ser feita envolve o potencial de energia do produto que apresenta a mistura de dois materiais distintos, em outras palavras, a embalagem de alumínio-PVC comumente utilizada e descartada em aterros, desconsidera o ganho energético com o reaproveitamento de resíduo, inviabilizando a produção, do ponto de vista de impacto ambiental, em comparação com as demais situações (alumínio-alumínio, PVC-PVC, papel-papel). Os Blisters simulados de um mesmo material, uma vez que podem ser reciclados, apresentam valores totais de energia relativamente mais baixos que o de alumínioPVC.

O blister contendo apenas papel apresentou redução significativa de $88 \%$ de gasto de energia, e aproximadamente $89 \%$ na redução de emissões de $\mathrm{CO}_{2}$, em comparação com a embalagem considerada tradicional, alumínio-PVC. Para as demais embalagens sem mistura de materiais, houve uma redução de, respectivamente, $75 \%$ de gasto de energia e $67 \%$ de emissões de $\mathrm{CO}_{2}$ para 0 alumínio e cerca de $57 \%$ de gasto de energia e $55 \%$ de emissões de $\mathrm{CO}_{2}$ para o Blister feito apenas de PVC.

Tabela 7 - Resultado da Simulação com o Software Eco Audit $\AA$

BLISTER DE MEDICAMENTO

\begin{tabular}{|c|c|c|c|}
\hline Produto & $\begin{array}{c}\text { Energia Incorporada } \\
\text { (MJ) }\end{array}$ & $\begin{array}{l}\text { Potencial de Energia EoL } \\
\text { (MJ) }\end{array}$ & $\begin{array}{c}\text { Energia Total } \\
(\mathrm{MJ})\end{array}$ \\
\hline Alumínio-Alumínio & 1.199 .000 & -986.607 & 212.393 \\
\hline Alumínio-PVC & 857.181 & 0 & 857.181 \\
\hline PVC-PVC & 746.708 & -382.027 & 364.682 \\
\hline Papel-papel & 242.137 & -141.101 & 101.036 \\
\hline Produto & Pegada de $\mathrm{CO}_{2}(\mathrm{~kg})$ & Potencial de $\mathrm{CO}_{2}$ - EoL (kg) & $\mathrm{CO}_{2}$ Total $(\mathrm{kg})$ \\
\hline Alumínio-Alumínio & 77.890 & -61.273 & 16.618 \\
\hline Alumínio-PVC & 49.767 & 0 & 49.767 \\
\hline PVC-PVC & 40.768 & -18.587 & 22.181 \\
\hline Papel-papel & 5.476 & -196 & 5.280 \\
\hline
\end{tabular}

As estimativas e simulações apresentadas com potenciais combinações de materiais, onde considerou-se no projeto a questão ecológica nos aspectos funcionais e geométricos, além das propriedades dos materiais empregados, resultaram na redução do impacto ambiental. Essa redução foi caracterizada pela diminuição do gasto de energia incorporada, Figura 5, e na redução das emissões 
de $\mathrm{CO}_{2}$, Figura 6. Estas reduções foram influenciadas pela recuperação de parte dos materiais ao final da vida do produto, possível devido à preocupação com a reciclagem, bem como, pela consideração de aspectos funcionais, geométricos e de materiais para diminuição da massa de resíduos gerados e da energia incorporada.

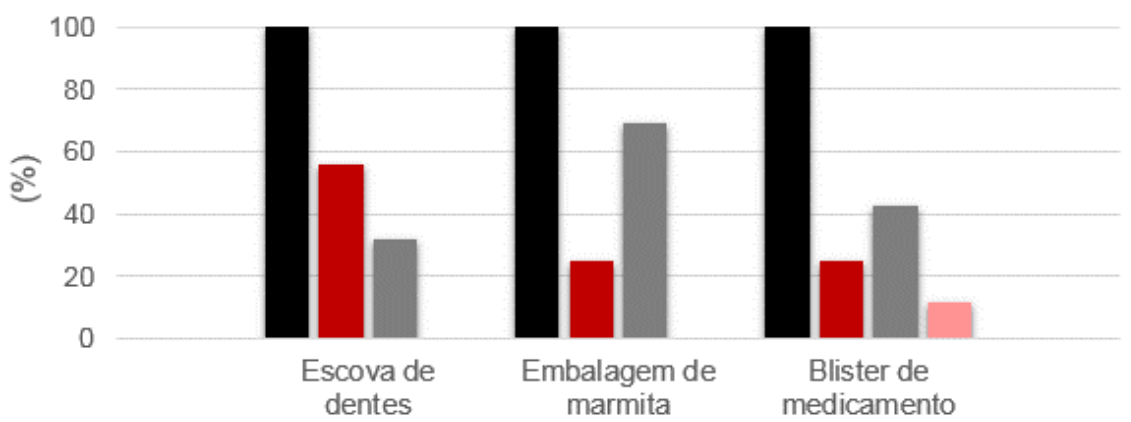

-Escova de dentes- material misturado; Embalagem de marmita- Al; Blister de medicamentoPVC-AI.

- Escova de dentes- Sem mistura, translúcido; Embalagem de marmita- Isopor; Blister de medicamento- PVC/PVC.

- Escova de dentes- Sem mistura, translúcido, cabeça removível; Embalagem de marmita- papel

Blister de medicamento- Al

- Blister de medicamento- Papel.

Figura 5. Diminuição no gasto de energia incorporada

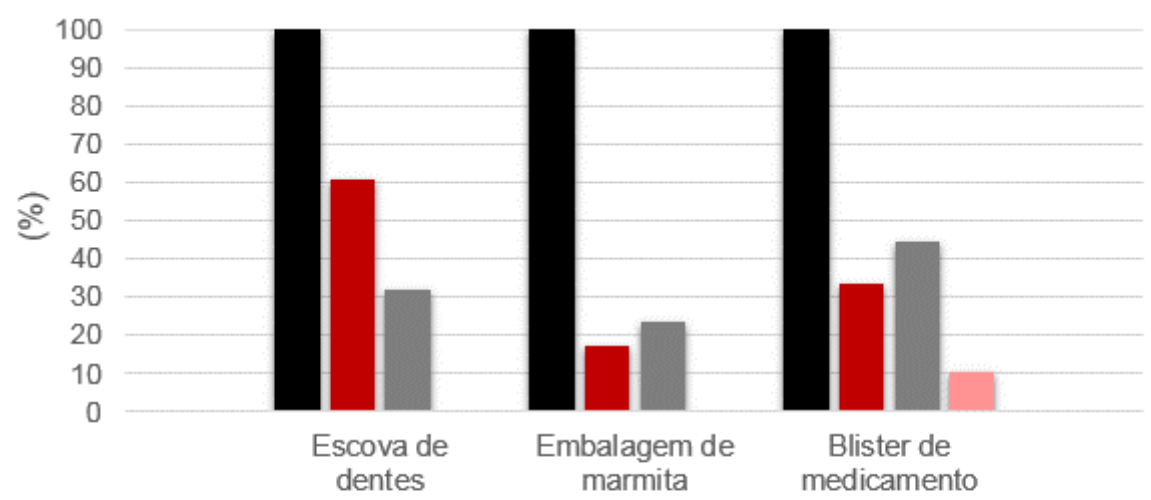

- Escova de dentes- material misturado; Embalagem de marmita- Al; Blister de medicamentoPVC-Al.

- Escova de dentes- Sem mistura, translúcido; Embalagem de marmita- Isopor; Blister de medicamento- PVC/PVC.

- Escova de dentes- Sem mistura, translúcido, cabeça removível; Embalagem de marmita- pape Blister de medicamento- Al

Blister de medicamento- Papel.

Figura 6. Diminuição nas emissões de $\mathrm{CO}_{2}$.

\section{CONCLUSÃo}

Considerando os produtos estudados, as simulações realizadas apresentaram possibilidade de redução considerável no impacto ao meio ambiente. Para o primeiro produto simulado, a escova de dentes, considerando-se o cabo de um único material, translúcido e com cabeça removível, a redução de energia incorporada e nas emissões de $\mathrm{CO}_{2}$ chegou a $68 \%$. Para a embalagem de marmita, a redução de energia incorporada e nas emissões de $\mathrm{CO}_{2}$ foi maior para o isopor, alcançando-se $75 \%$ e $81 \%$, respectivamente, porém, vale ressaltar que apesar do papel ter ficado com $31 \%$ e $76 \%$, respectivamente, ele é um material biodegradável. Por fim, para o 
blister de medicamento, se este fosse fabricado de papel em vez do tradicional de PVC com alumínio, haveria uma redução de $88 \%$ de energia incorporada e $89 \%$ de emissões de $\mathrm{CO}_{2}$.

\section{Agradecimentos}

Ao Centro Universitário da FEl pela oportunidade da realização deste Trabalho.

\section{REFERÊNCIAS}

[1] NUNES, P., 2016. Sociedade do Consumo. Disponível: http://knoow.net/ cienceconempr/economia/sociedade-de-consumo/. Acesso em 05/08/2016.

[2] BAIMA, C. Plástico forma Ilhas de Poluição no Oceano. O Globo - Ciência. 04 de nov. 2011. Disponível: http://oglobo.globo.com/sociedade/ciencia/ plastico-formailhas-de-poluicao-nos-oceanos-2962119

[3] ASHBY, F.; SHERCLIFF, H., CEBON, D. Materiais - Engenharia, Ciência, Processamento e Projeto. 2. ed., p.514-535, 2012.

[4] ABIPLAST; CNRMP. Reciclabilidade de Materiais Plásticos Pós-consumo. São Paulo, 2015. Disponível: http://file.abiplast.org.br/download/2016/ cartilha_reciclabilidade_abiplast_web_3.pdf. Acesso em:05/09/2016.

[5] SILVA, H. C. O. Marketing e Sustentabilidade: Uma Análise dos Avanços

Teóricos e Práticos no Campo do Marketing Sobre a Perspectiva da

Sustentabilidade Socioambiental. São Paulo, 2011.

[6] AKATU. Pesquisa AKATU 2012: Rumo à Sociedade do Bem-estar. 1. Ed., São Paulo, 2013. Disponível: http://www.akatu.org.br/pesquisa/2012/ PESQUISAAKATU.pdf. Acesso em:03/08/2016.

[8] ASHBY, M.F.; COULTER, P., Ball, N.; BREAM, C. (2009). White Paper. The CES EduPack Eco Audit Tool. University of Cambridge \& Granta Design Ltd., Cambridge. .Acesso em: 24/08/2016;

[7] HERRERA, J. A. Q. Quantificação e correlação das variáveis do ciclo de vida energético da edificação: energia incorporada na envolvente arquitetônica e consumo energético pelo comportamento térmico, caso de estudo: moradia. São Carlos, 2013.

[9] ASHBY, M. F. Materials Selection in Mechanical Design. 3. ed., 2005.

[10] SINDUSCON-SP, 2016. Construção brasileira demitiu 467,7 mil trabalhadores em 12 meses. Disponível: http://www.sindusconsp.com.br/release/construcaobrasileira-demitiu-4677-mil-trabalhadores-em-12-meses/. Acesso em: 06/09/2016.

[11] IBGE, 2016. Projeção da População do Brasil e das Unidades da Federação. Disponível: http://www.ibge.gov.br/apps /populacao/projecao/. Acesso em: 04/09/2016.

[12] REDAÇÃO, 2015. Aumenta em 161\% o consumo de medicamentos controlados no país. Agência Senado. Disponível em: http://www12.senado.

leg.br/noticias/materias/2015/05/20/aumenta-em-161-o-consumo-de-medicamentoscontrolados-no-pais. Acesso em: 04/09/2016. 